\title{
PREDICTION OF THE ULTIMATE LONGITUDINAL COMPRESSIVE CONCRETE STRAIN AT HOOP FRACTURE USING ENERGY CONSIDERATIONS
}

\author{
H. Tanaka ${ }^{1}$ and R. Park ${ }^{2}$
}

\begin{abstract}
The fracture of transverse boop ceinforcement can lead to the collapse of a reinforced concrete column, as has been observed in concrete bridges and buildings attacked by severe earthquakes as well as in laboratory tests. To predict the longitudinal concrete strain at the stage of first hoop fracture a theoretical method based on considerations of strain energy referred to as "Energy Balance Theory" has been proposed by Mander et al. This paper reviews the "Energy Balance Theory" and then proposes several modifications for this theory based on a failure model of a reinforced concrete column subject to axial compression. These modifications take into account significant energy factors neglected in the theory by Mander et al and correct some unrealistic assumptions made in that theory. The predictions of the modified theory are then compared with the results obtained from concentric loading tests on 18 reinforced concrete columns conducted at the University of Canterbury and the validity of the modified theory is assessed.
\end{abstract}

\section{NOTATION}

\begin{tabular}{|c|c|}
\hline & $\begin{aligned} & \text { sectional area of concrete core } \\
& \text { measured to centre of peripheral } \\
& \text { spiral or hoop }\end{aligned}$ \\
\hline${ }^{A} \mathrm{CO}$ & $\begin{array}{l}=\text { sectional area of concrete cover } \\
=\text { sectional area of a longitudinal } \\
\text { bar }\end{array}$ \\
\hline & $\begin{aligned}= & \text { maximum lateral deflection of a } \\
& \text { longitudinal bar due to buckling }\end{aligned}$ \\
\hline$d_{b}$ & $\begin{array}{l}=\text { diameter of a hoop bar } \\
=\text { core diameter of a reinforced } \\
\text { concrete column }\end{array}$ \\
\hline${ }^{E}{ }_{b}$ & $\begin{array}{l}=\text { tangent modulus of a longitudinal } \\
\text { bar in the inelastic range }\end{array}$ \\
\hline & $\begin{array}{l}=\text { compressive stress in confined } \\
\text { concrete in the column core }\end{array}$ \\
\hline & $\begin{aligned} &= \text { axial stress component in core } \\
& \text { concrete due to friction between } \\
& \text { shear sliding surfaces }\end{aligned}$ \\
\hline & $\begin{array}{l}\text { compressive stress in unconfined } \\
\text { concrete in the column concrete } \\
\text { cover }\end{array}$ \\
\hline & $\begin{array}{l}\text { compressive strength of plain } \\
\text { concrete assumed to be } 85 \% \text { of the } \\
\text { control cylinder strength }\end{array}$ \\
\hline
\end{tabular}

1 Department of Architectural. Engineering,

Akashi Technological College, Japan.

Department of Civil Engineering, University of Canterbury, New Zealand.

\begin{tabular}{|c|c|c|}
\hline & & $\begin{array}{l}\text { tensile stress } \\
\text { reinforcement }\end{array}$ \\
\hline & $=$ & $\begin{array}{l}\text { compressive stress in longitudinal } \\
\text { reinforcement }\end{array}$ \\
\hline & & ultimate tensile strength of stee \\
\hline & $=$ & $\begin{array}{l}\text { moment of inertia of longitudinal } \\
\text { bar cross section }\end{array}$ \\
\hline & & $\begin{array}{l}\text { agreement index of the proposed } \\
\text { theory to the experimental value } \\
\text { defined by Eq. } 23\end{array}$ \\
\hline $\mathrm{ac}$ & & $\begin{array}{l}\text { agreement index of the energy } \\
\text { balance theory to the experimental } \\
\text { value defined by Eq. } 24\end{array}$ \\
\hline & $=$ & $\begin{array}{l}\text { compressive stiffness of cov } \\
\text { concrete }\end{array}$ \\
\hline & & $\begin{array}{l}\text { compressive stiffness of core } \\
\text { concrete before complete formation } \\
\text { of shear sliding surfaces }\end{array}$ \\
\hline & & $\begin{array}{l}\text { compressive stiffness of core } \\
\text { concrete after complete formation } \\
\text { of shear sliding surfaces }\end{array}$ \\
\hline & $=$ & $\begin{array}{l}\text { compressive } \\
\text { compression reinforcement }\end{array}$ \\
\hline & & $\begin{array}{l}\text { stiffness of hoop reinforcement as } \\
\text { lateral confinement }\end{array}$ \\
\hline & $=$ & $\begin{array}{l}\text { initial length of a longitudinal } \\
\text { bar before loading }\end{array}$ \\
\hline & $=$ & $\begin{array}{l}\text { gauge length for strain } \\
\text { measurement in core concrete }\end{array}$ \\
\hline & $=$ & $\begin{array}{l}\text { axial load on core concrete } \\
\text { axial load on cover concrete }\end{array}$ \\
\hline & & axial load on compres \\
\hline
\end{tabular}




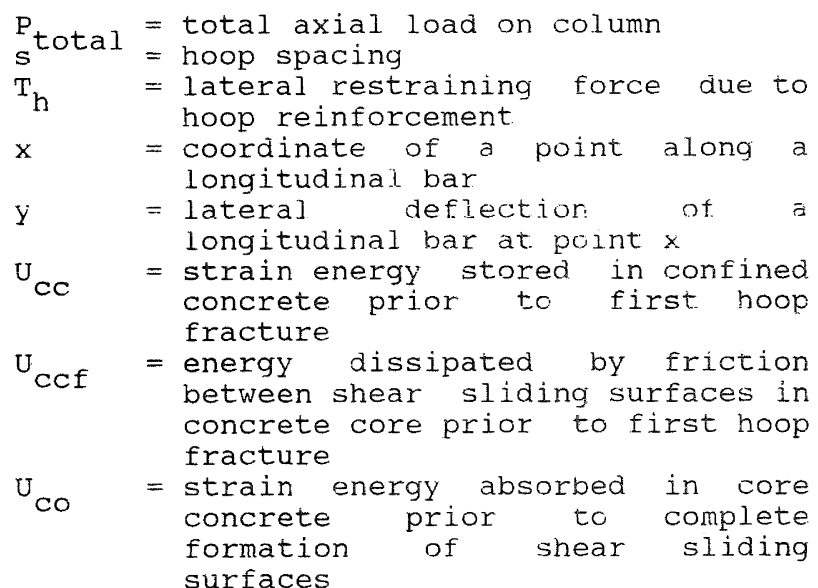

$\mathrm{U}_{\mathrm{cov}}=$ strain energy absorbed in cover concrete prior to complete spalling

$\mathrm{U}_{\mathrm{g}} \quad$ external work done on an axially loaded column

$\mathrm{U}_{\mathrm{SC}}=$ external work done on compression reinforcement

$\mathrm{U}_{\mathrm{scr}}=$ strain energy absorbed in compression reinforcement by axial yeilding

$\mathrm{U}_{\text {sh }}=$ strain energy capacity of hoop reinforcement at the fracture strain of that steel

$\mathrm{U}^{\prime} \mathrm{sh}$ = strain energy stored in hook reinforcement at first hoop fracture in case where compression reinforcement has not buckled or has buckled within one hoop spacing

= reduction determined factor for from sh distribution in hoops along the column axis

$\beta$ = ratio of strain energy absorbed in compression reinforcement by axial yielding to external work done on compression reinforcement

$\gamma \quad=$ constant determined by magnitude of friction between shear sliding surfaces in concrete core

= lateral deflection of a longitudinal bar at hoop position

$=$ longitudinal compressive strain in core and cover concrete

= ultimate longitudinal compressive strain of confined concrete defined as that strain at the stage of first hoop fracture

= axial strain in compression reinforcement at the onset of buckling

= apparent axial strain in compression reinforcement due to axial shortening caused by bar buckling

${ }^{\epsilon}$ sh = tensile strain in hoop reinforcement

= fracture strain of hoop steel bar

sf $=$ longitudinal compressive strain in

sp core concrete at which shear sliding surfaces are assumed to be completely formed simultaneousiy with the completion of spallina of cover concrete $\begin{aligned} \mathrm{s} \quad= & \text { longitudinal compressive strain in } \\ & \text { a longitudinal bar with hoop } \\ & \text { spacing of } s \text { when bar buckling } \\ & \text { commences }\end{aligned}$

$\begin{array}{rlrl}\mu_{\mathrm{CC}}= & \text { sectional area ratio of } \\ & \text { compression reinforcement } & \text { to } \\ & \text { concrete core } & \\ \omega_{\mathrm{s}} & \text { volumetric ratio of hoop } \\ & \text { reinforcement to concrete core } \\ { }_{t}= & \text { sectional area ratio of } \\ & \text { longitudinal reinforcement to } \\ & \text { gross column section }\end{array}$

\section{INTRODUCTION}

When a reinforced concrete column well confined by hoop reinforcement is loaded to failure, fracture of the hoop reinforcement eventually occurs and results in a sudden drop in load carrying capacity of the section due to a reduction in confinment of the core concrete and a loss of buckling restraint for the longitudinal bars. This stage of failure signals the destruction of the column. Hence hoop fracture should be avoided within an expected range of column deformation under any design load condition especially such as the deformations imposed by a severe earthquake. In order to provide such a restriction to the column deformation, a method for the prediction of the available maximum deformation of the column section limited by the occurrence of hoop fracture is required. The available maximum deformation of a column section could be expressed in terms of an ultimate longitudinal compressive strain of the core concrete at an associated curvature.

Mander et al $[1,2,3]$ have proposed a theory for the prediction of the ultimate longitudinal compressive concrete strain at the stage of first hoop fracture referred to as the "Energy Balance Theory". The ultimate longitudinal compressive concrete strain at first hoop fracture predicted by this theory agreed well with most of the accompanied test rseults [1]. However, the theory as presented by Mander et al is simplified and may not always give an adequate estimation of the ultimte concrete strain at first hoop fracture for the following two reasons.

Firstly, in the main energy equation used in the theory, the relation between the strain energy stored or dissipated in the core and cover concrete, longitudinal bars and hoops was simplified by neglecting several energy factors which might not be negligible. For example, the treatment of the strain energy absorbed in the longitudinal bars seems to be inadequate, especially when buckling of the longitudinal bars commences at large axial strain.

Secondly, the strain energy stored in the hoops prior to first hoop fracture could be overestimated by about 20 to $40 \%$ or more if the value proposed, based on tensile tests on steel bars, was used. The value proposed for the strain energy stored in the hoops prior to first hoop fracture was determined by assuming that all regions of the hoop (that is, the whole length of hoop) reached the fracture strain at the same time. It is more reasonable to consider that at first hoop fracture the strains in the all parts of the hoop bar except the small length which necks and fractures will be same or less than the strain at ultimate strength of the hoop bar 
which is usually 20 to $40 \%$ less than the fracture strain of the hoop bar.

This probable overestimation of the strain energy stored in the hoops prior to first hoop fracture appears to have compensated for the omission of the absorbed energy in the longitudinal bars when the theory was applied by Mander et al to test results. However, a significant error in the estimation of the ultimate longitudinal compressive concrete strain at first hoop fracture can possibly be made in the case of a column with a combination of a large amount of longitudinal bars and a small amount of hoop reinforcement or in case of a column which has a large strain gradient in the section caused by bending.

In this paper, after discussing in more detail the problems in the energy balance theory proposed by Mander et al, a modified theory for the prediction of the ultimate longitudinal compressive concrete strain at which first hoop eracture occurs is proposed using a simple failure model of a reinforced concrete column under axial compression load.

THE ENERGY BALANCE THEORY PROPOSED BY MANDER ET AL

The Basis of the Theory by Mander et aI

Many experimental studies have demonstrated that the compressive strength and ductility of the core concrete in a reinforced concrete member can be enhanced using closely spaced transverse confining reinforcement in the form of spirals or hoops with or without cross ties. As an example, stress-strain relations obtained from compression tests on three sets of circular columns with spirals tested by Iyenger et al [4] are shown in Fig.1. Schematic stress-strain curves of confined and unconfined concrete can be represented by Fig. 2 [1,2,3]. The area under each curve represents the total strain energy per unit volume required to 'fail' the concrete and the shaded area indicates the increase in strain energy to failure resulting from confinement. Here the failure of the confined concrete is defined as the stage of first hoop fracture.

In the energy balance theory proposed by Mander et al $[1,2,3]$, it was assumed that the ultimate strain energy capacity of the transverse confining reinforcement per unit volume of concrete core ( $U_{\mathrm{sh}}$ ) could be equated to the difference in area between the confined ( $U_{C S}$ ) and unconfined ( $U_{U}$ ) stress-strain curves (that is, the shaded area in Fig.2) plus the stored strain energy in the compressed longitudinal reinforcement per unit volume of concrete core ( $\mathrm{U}_{\mathrm{SC}}$ ). This was expressed in the form

$$
U_{s h}=\left(U_{c c}-U_{c o}\right)+U_{S C}
$$

The Strain Energy Absorbed by the Longitudinal Reinforcement

It is evident that the assumption of the energy balance theory expressed in the form of Eq.1 is not always adequate. For example, the use of Eq.1 can result in a large error in case of a column which has a large amount of longitudinal reinforcement compared with the amount of transverse confining reinforcement, as can be demonstrated by the following check. If transverse confining reinforcement is not provided, then $U_{S h}=0$ which from Eq.1 means that

$$
\mathrm{U}_{\mathrm{SC}}=\mathrm{U}_{\mathrm{CO}}-\mathrm{U}_{\mathrm{CC}}
$$

But for this case $U_{\text {D }}-U_{\text {is }}$ is equal to zero if there is cono confinement, or $U$ - U is less than zero if some confininğ effect by the longitudinal reinforcement can be expected, and hence $\mathrm{U} \leq 0$. However, $U$ can be neither zero nô negative since the longitudinal reinforcement is acting as compression reinforcement. Hence, Eq. 1 yields a contradiction in this case.

A further check for Eq.I can be conducted as follows. The theory indicates that Eq.1 can be rewritten for per unit volume of concrete core in terms of strains and stresses as

$$
\begin{aligned}
& \rho_{s} \int_{0}^{\dot{s} f} \mathrm{f}_{s h} \mathrm{~d} \epsilon_{s h}=\iint_{0}^{c u} \mathrm{f}_{c c} \mathrm{~d} \epsilon \mathrm{c} \\
& \left.-\int_{0}^{t} \operatorname{sp} \mathrm{E}_{c o} \mathrm{~d} t c\right)+\rho_{c c} \int_{0}^{c u} \mathrm{f}_{\mathrm{Sl}} \mathrm{dt} c
\end{aligned}
$$

or for per unit length of the column as

$$
\begin{aligned}
& A_{c c^{\rho} s} \int_{0}^{t} \operatorname{sf} f_{s h} d \epsilon=\left(A_{c c} \int_{0}^{c u} f_{c c} d t c\right. \\
& -A_{c c} \int_{0}^{t}{ }^{s p} f_{c o} d t c A_{c c} d c c \int_{0}^{c u} \mathrm{f}_{s 1} d t c
\end{aligned}
$$

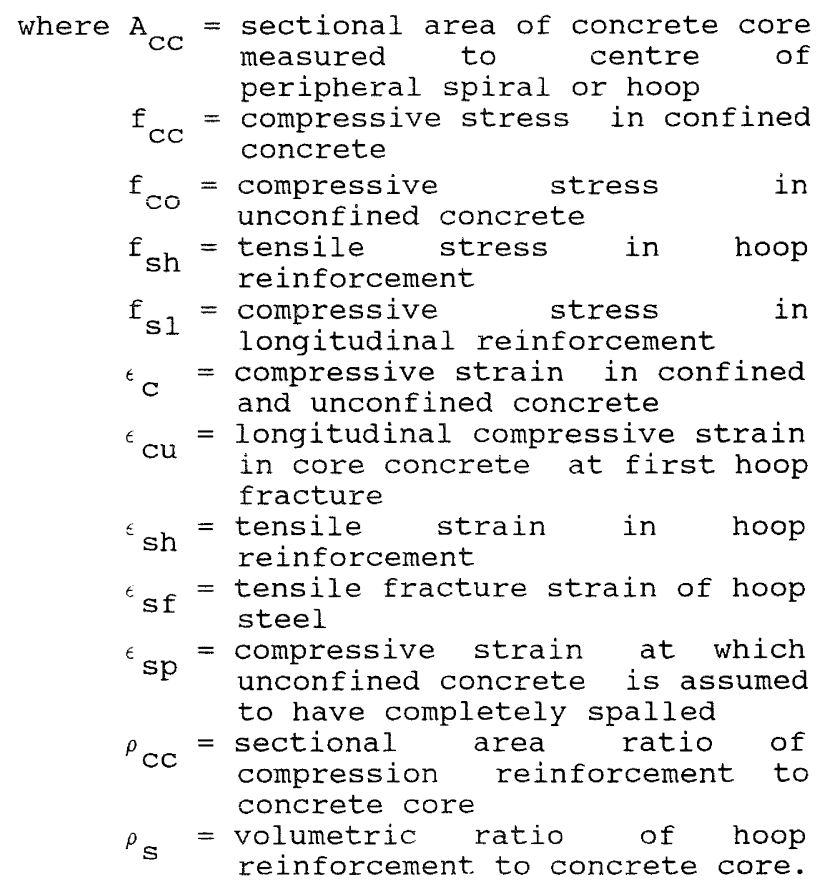




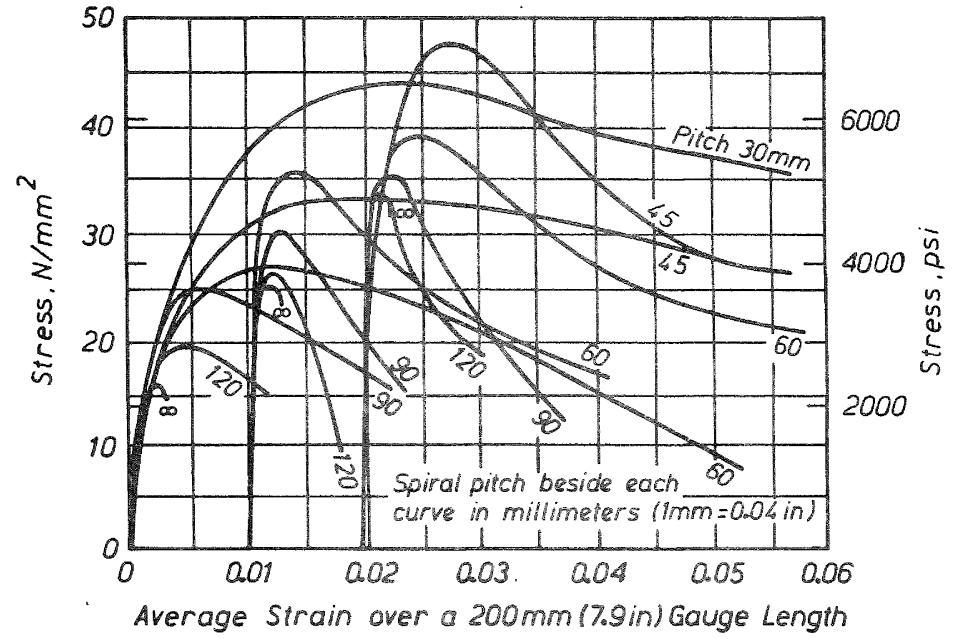

Fig. 1 stress-strain curves for concrete cylinders $150 \mathrm{~mm}$ ( $5.9 \mathrm{in}$ ) Diameter by $300 \mathrm{~mm}$ (11.8 in) High, Confined by Circular spirals from $6.5 \mathrm{~mm}(0.26$ in) Diameter Mild steel Bar [4]

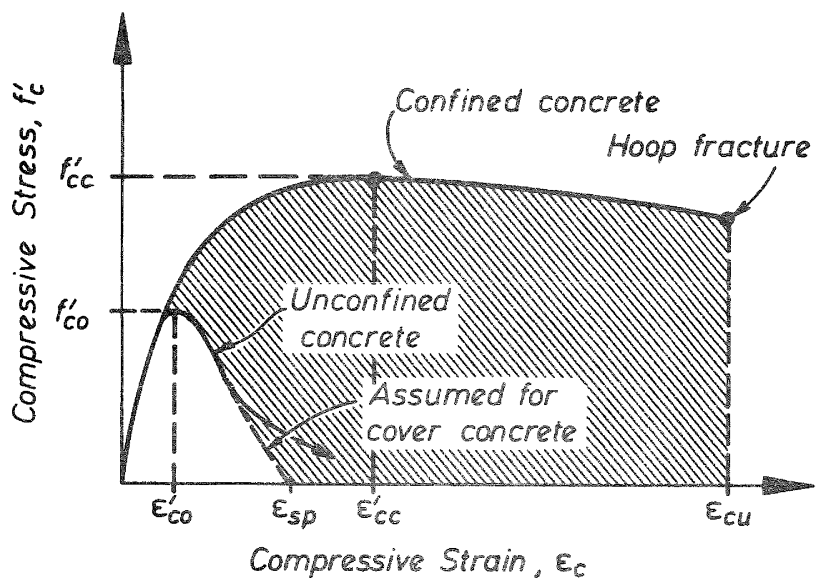

Fig. 2 Stress-Strain Model for Confined and Unconfined Concrete $[1,2,3]$

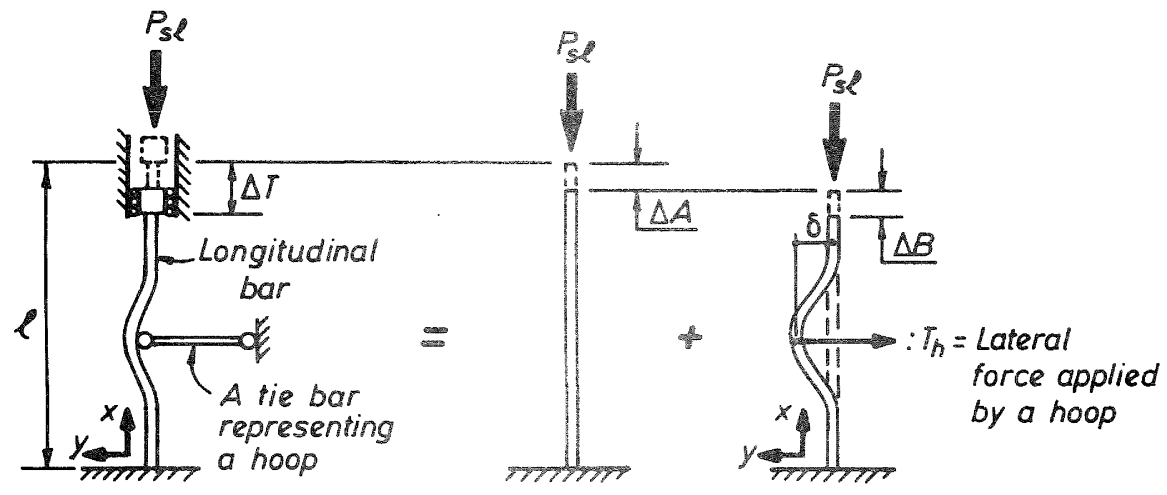

Axial Shortening Axial Shortening

due to due to

Compression Buckling 
Note that for the calculation of $U$ in the last term in Eqs.3 and 4, de scas used instead of $d t_{s}$ where $\epsilon_{s}=$ axial compressive strain in the longituánal bars. However the axial strain of the concrete core will only be equal to the axial strain in the longitudinal bars before buckling of the longitudinal bars occurs and provided that there is no bond slip of the longitudinal bars. once buckling of the longitudinal bars has commenced the strain $t$ should be expressed as the sum of the axial compressive strain of the longitudinal bars $\epsilon$ and an apparent strain due to the axial shortening of the longitudinal bars induced by the bar buckling $\epsilon^{\prime} s^{\circ}$ This can be expressed in the form

$$
\epsilon_{c}=\epsilon_{S}+\epsilon^{\prime} s
$$

The buckled condition of a longitudinal bar may be modelled as shown in Fig.3. The total axial displacement $\Delta T$ can be separated into the displacement due to the axial compression $\Delta \mathrm{A}$ and the displacement due to the buckling $\Delta B$. $\epsilon^{\epsilon} \mathrm{C}^{\prime}{ }^{t} \mathrm{~s}$ and $\epsilon^{\prime}{ }_{\mathrm{S}}$ in $E q .5$ correspond to $\Delta T / 1,{ }^{\prime} \Delta A / 1$ and $S B / 1$ respectively, where $I$ is the initial length of the bar before loading. The energy relation between the external work done by the axial force $P$ and the corresponding strain energy in $\mathrm{Sh}_{\mathrm{h}}$ longitudinal bar and the hoop reinforcement can be written in the form

$$
\begin{gathered}
P_{S 1} \Delta T=P_{S 1} \Delta A+P_{S 1} \Delta B \\
=A_{S} \int_{0}^{\epsilon} f_{s 1} d \epsilon_{s}+\left[\int_{0}^{1} \frac{E_{b} I_{b}}{2}\left(\frac{d^{2} y}{d x^{2}}\right)^{2} d x\right. \\
\left.+\int_{0}^{\delta} T_{h} d \delta\right]
\end{gathered}
$$

$$
\begin{aligned}
& \text { where } A_{S}=\begin{array}{l}
\text { sectional area } \\
\text { longitudinal bar }
\end{array} \\
& \mathrm{E}_{\mathrm{b}}=\begin{array}{l}
\text { tangent modulus of a } \\
\text { longitudinal bar in the }
\end{array} \\
& \begin{array}{l}
\text { longitudinal bar } \\
\text { inelastic range }
\end{array} \\
& I_{b}=\text { moment of inertia of } \\
& \text { longitudinal bar cross section } \\
& \mathrm{T}_{\mathrm{h}}=\text { lateral restraining force due } \\
& \text { to hoop reinforcement } \\
& \delta=\text { lateral deflection of a } \\
& \mathrm{d}^{2} \mathrm{y} / \mathrm{dx} \mathrm{x}^{\text {position }} \\
& \text { = curvature of a longitudinal bar } \\
& \epsilon_{\mathbf{s}}=\text { axial strain due to stress } \\
& \mathrm{f}_{\mathrm{SI}}=\mathrm{P}_{\mathrm{sl}} / \mathrm{A}_{\mathrm{s}}
\end{aligned}
$$

In this paper only inelastic buckling of a longitudinal bar is considered because the spacing of the hoop sets is normally close enough to prevent elastic buckling as specified in the New Zealand design code for reinforced concrete structures [5]. Hence, in Eq.6, the first term in the square parentheses expresses the strain energy stored in a longitudinal bar due to bending during inelastic buckling using tangent modulus theory [6], while other theories of inelastic buckling $[7,8,9]$ might give more accurate estimation. However, which theory is the most suitable is not so important here because the magnitude of the strain energy of that term is found to be considerably smaller than other terms in Eq. 6 due to small bending stiffness of the longitudinal bar in the inelastic range and thus that term may be neglected.

Now, reconsider the meaning of Eq. 4 here. Rearranging Eq.4,

$$
\begin{aligned}
& A_{c c} \int_{0}^{\epsilon} \mathrm{f}_{c c} \mathrm{~d} \epsilon_{c}+A_{c c}{ }^{\rho} c c \int_{0}^{c u} \mathrm{f}_{s 1} \mathrm{~d} \epsilon \\
& =A c c^{\rho} s \int_{0}^{\varepsilon} \mathrm{sf} \mathrm{sh}^{\mathrm{d} \epsilon} c+A c c \int_{0}^{\epsilon} \mathrm{sp} \mathrm{f}_{c o} \mathrm{~d} \epsilon
\end{aligned}
$$

The left hand side of the equation is almost equivalent to the external work done on an axially loaded column per unit length $\left(U_{g}\right)$. To be more precise, the external work per unit length of the column $U_{g}$ can
be expressed in the form

$$
\begin{aligned}
& \mathrm{U}_{\mathrm{g}}=\mathrm{U}_{\mathrm{cc}}+\mathrm{U}_{\mathrm{SC}}+\mathrm{U}_{\mathrm{cov}} \\
& =A_{c c} \int_{0}^{\epsilon} f_{c c} d \epsilon+A_{c c}{ }^{\rho} c c \int_{0}^{c u} f_{s 1} d \epsilon c \\
& +A_{\operatorname{cov}} \int_{0}^{t} \mathrm{sp}{ }_{c o} d t
\end{aligned}
$$

where $\mathrm{U}_{\mathrm{Cov}}=$ strain energy absorbed in cover concrete prior to complete spalling

$\mathrm{A}_{\mathrm{Cov}}=$ sectional area of concrete cover

Note that all the integrations are against $d \epsilon{ }_{C}$.

The energy absorbed by the cover concrete $\mathrm{U}$ cov is usually only a small fraction of UCovecause cover concrete area is usually mulch smaller than the core concrete area and the strain at spalling is also smaller than the ultimate concete core strain (see $U$ in Table 2). Therefore, U can be approximated by the terms on the 1 fet hand side of Eq.7. The meaning of Eq.8 can be reconfirmed by recalling the typical procedure used to determine the stressstrain relation of confined concrete from a conrentric loading test on a reinforced concrete column. As the first step, a total load versus axial strain relation, Curve (A) in Fig.4, is obtained from the measurement of the machine load and corresponding axial displacement within the gauge length. Secondiy, the axial load sustained by the longitudinal bars at each corresponding axial strain is estimated using a stress-strain relation obtained from tensile or compression tests on the identical bars. The curve (B) in Fig.4 indicates the case where the reduction of the axial stress in the longitudinal bars due to buckling is negligible. Thirdly, the axial load sustained by the cover concrete, curve (C), is estimated from the stress-strain relation obtained from 
compression tests on plain concrete specimens or control cylinders. Finally, the axial load sustained by the core concrete $\left(\mathrm{P}_{C C}\right)$ can be determined by subtracting ${ }^{C}$ he loads sustained by the longitudinal bars $\left(\mathrm{P}_{\mathrm{B}}\right)$ and the cover concrete $\left(\mathrm{P}_{\mathrm{CPV}}\right)$ from the total load $\left(P_{1}\right)$. Cove stress in the confined concrete can be found by dividing $F$ by $A$ and then the stress-strain curve of confined concrete can be drawn as shown in Fig.2. Therefore, the external work done by the loading machine for a unit length of the column can be expressed in the form

$$
\begin{aligned}
U_{g} & =\int_{0}^{c} P_{\text {total }} P_{c} d t=\int_{0}^{c u} P_{c c} d t c \\
& +\int_{0}^{c u} P_{s 1} d t c+\int_{0}^{s p} P_{c o v} d t c
\end{aligned}
$$

Eq.9 is identical with Eq.8.

Hence, it can be considered that the left hand side in Eq.7 is almost equivalent to the external work done on the column. Now some part of the external work done on the column by the loading machine should be transferred to the longitudinal bars. However, a term with the strain energy directly related to the longitudinal bars can not be found in the right hand side of Eq.7. Therefore, to ensure that the terms on the right hand side of Eq.7 are adequate, all of the external work done on the longitudinal bars needs to be transferred to the hoop reinforcement. In this case, in Eq. 6, this requires that

$$
A_{s} 1 \int_{0}^{t} f_{s 1} d \epsilon=0 \text { and } \int_{0}^{1} \frac{E_{b} I_{b}}{2}\left(\frac{d^{2} y}{d x^{2}}\right)^{2} d x=0
$$

To satisfy the above conditions, it would be necessary to assume that the buckling of the longitudinal bar occurs from the beginning of the loading, that the axial stiffness of the longitudinal bars is infinitively large and that the longitudinal bars have hinges free to rotate. This assumption can be modelled as shown in Fig.5. However, it is unrealistic to apply this model to the column reinforcement from the early stage of loading where the longitudinal bars have neither yeilded nor buckled. As a matter of course, this model can only be adequate from a certain stage of loading where the longitudinal bars have been compressed far into the plastic range and their bending stiffness has become negligibly small due to axial yielding.

on the other hand, if the axial force $P_{\text {}}$ reduces to zero due to serious buckling the elastic energy released from the longitudinal bars $U$ (which is represented by the shaded area in Fig.6) might be transferred to the hoop reinforcement. However, this elastic energy $U$ may be negligibly small compared with she total strain energy absorbed in: the longitudinai bars in the case where the hoop spacing and the amount of hoops are adequate to achieve sufficient ductility for a column during severe earthquake loading. For example, such serious buckiing can be expected only at very high axial compressive strain in the case of a column designed by the New Zealand concrete code [5] which is based on ductile design philosophy. Hence, it might be unnecessary to take into account this factor in Eq. 6 for a ductile column.

From the considerations described above, it can be predicted that Eq.1 may not be adequate except for a concrete column in which the strain energy stored in the longitudinal bars is quite small compared with the strain energy stored in the core concrete and in the hoop reinforcement.

The Strain Energy Capacity of the Transverse Reinforcement

Another problem exists in the term involving the strain energy capacity of the hoop reinforcement (U ) in Eqs. 3 and 4 . In the theory proposed ${ }^{S h}$ by Mander et al it was recommended that

$$
\int_{0}^{\mathrm{sf}}{ }_{\mathrm{fh}}^{\mathrm{f}} \mathrm{dt} s \mathrm{sh}=110 \mathrm{MJ} / \mathrm{m}^{3}
$$

be used to determine $U$. This value of Eq.10 was based on severâ tensile tests on reinforcing steel bars $[1,2]$. Note that the integration range in Eq. 10 is from zero to the hoop fracture strain : Usually, the measurement of fracture strain of a steel bar $\epsilon$ is significantly affected by the gauge leffith used in the tensile test. The strain distribution along the bar axis at the bar fracture can be represented as in Fig.7. It is evident that large strains concentrate over a small length of necked bar at the fracture. The fracture strain calculated from the elongation between points $A$ and $B$, which includes the necking part of the bar, is the average strain between those points. The corresonding stress-strain curves can be expressed as shown in Fig.8. The curves (1) and (2) are the stress-strain relations with a small and a large gauge length $A B$, respectively. If the necking part is not in the gauge length, that is for example the strain is measured between points $B$ and $C_{\text {; }}$ the stress-strain relation will follow curve (3) after reaching the ultimate stress $f_{\text {. Hence, the calculated strain }}$ energy capacity of the steel bar up to the hoop fracture, which corresponds to the area between the stress-strain curve and the strain axis, depends on the gauge

length. For example, in tests conducted by Tanaka [10] the calculated value of Eq.10 was found to vary from about $150 \mathrm{MJ} / \mathrm{m}^{3}$ with gauge length of $5 \mathrm{~d}_{3}$ (where $\mathrm{d}_{\mathrm{p}}=$ bar diameter) to $110 \mathrm{MJ} / \mathrm{m}^{3}$ with gauge length of $20 \mathrm{~d}$ and to 100 to $70 \mathrm{MJ} / \mathrm{m}^{3}$ for larger gauge lengths. The last values of 100 to $70 \mathrm{MJ} / \mathrm{m}^{3}$ were estimated using the relation, the strain energy stored at ultimate strength of steel per unit volume of reinforcement

$$
=\int_{0}^{\epsilon u} f_{s h} d \epsilon \text { sh }
$$




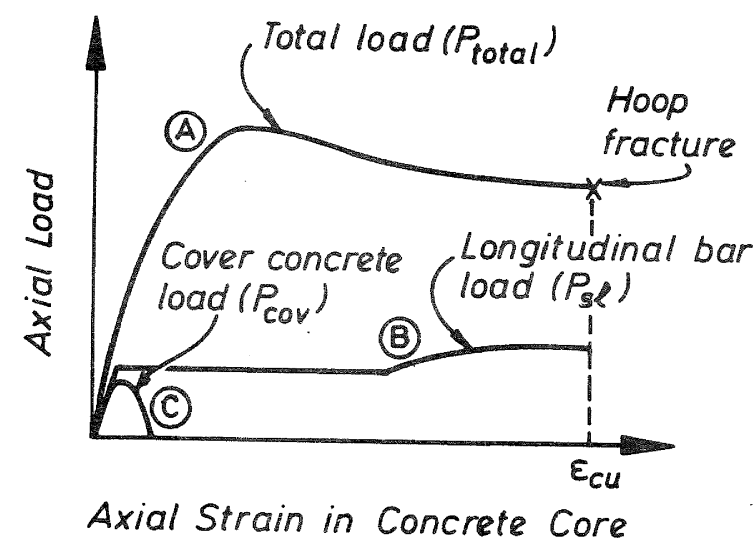

Fig. 4 Axial Load Components Versus Axial Strain Relation in a Reinforced Concrete Column

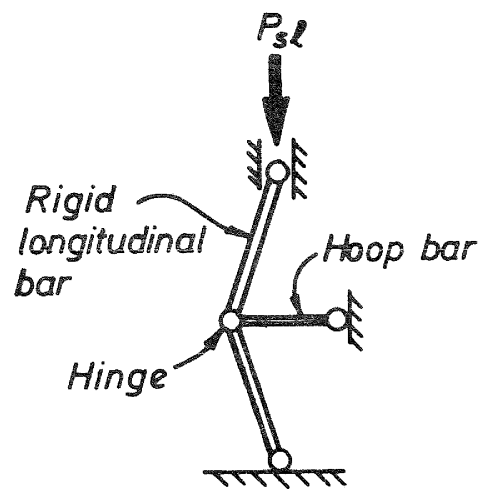

Fig. 5 Buckling Model for a Longitudinal Bar with Frictionless Hinges

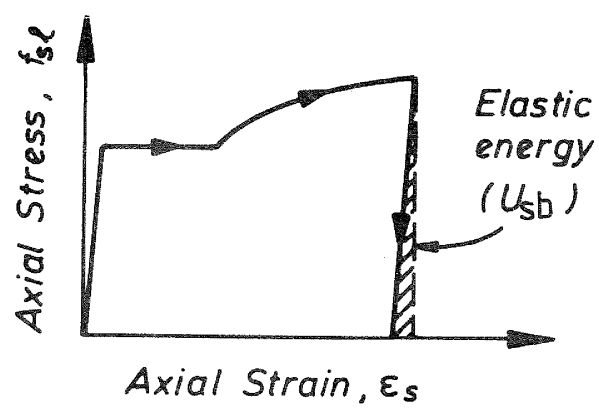

Fig. 6 Stress-Strain Curve for steel with Unloading Part

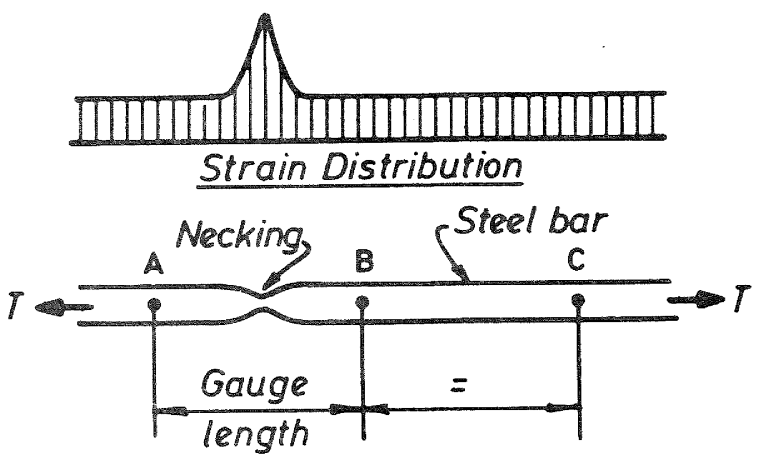

Fig. 7 Strain Distribution in a Steel Bar with Necking

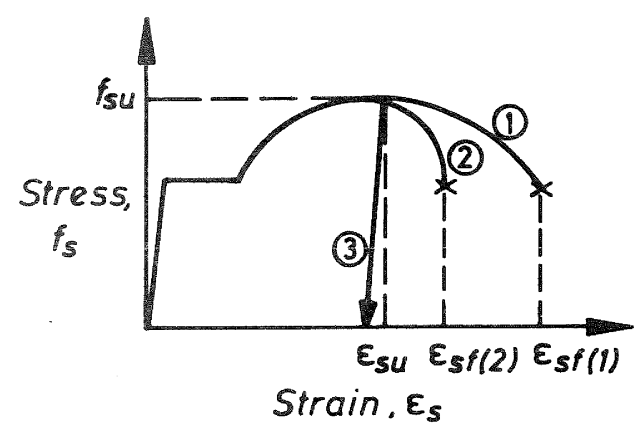

Fig. 8 Stress-Strain Curves for steel with Different Gauge Lengths

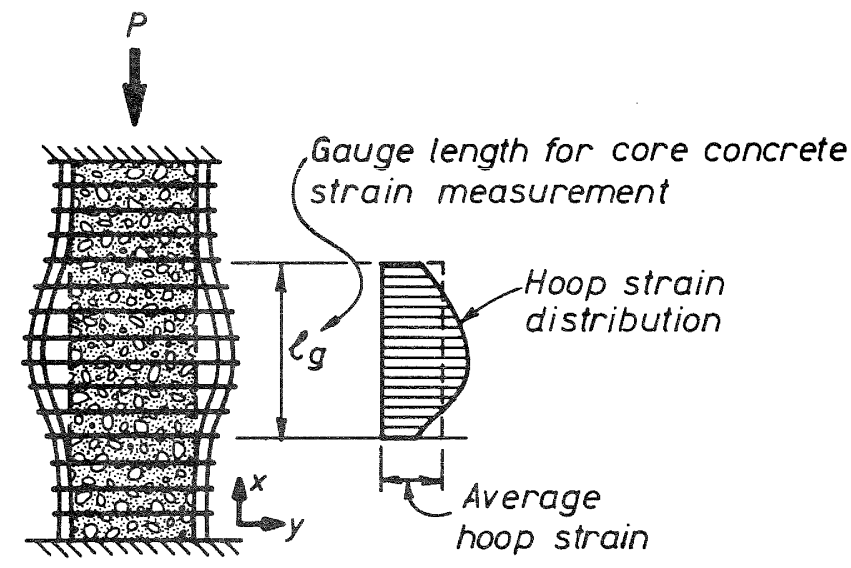

Fig. 9 Hoop Strain Distribution Along Column Axis with Longitudinal Bar Buckling 
where $\epsilon_{\text {su }}=$ strain at the ultimate tensile strengthu of steel (see Fig.8), instead of Eq.10. The details of these tests are described in the following section. Hence, the gauge length used in the measurement of strain needs to be properly chosen for the estimation of the strain energy capacity of the hoop reinforcement $U U$. For example, if circular spirals with 5 范 $\mathrm{mm}$ bar diameter are provided in a column with a concrete core diameter of $1 \mathrm{~m}$, the total length of the spiral in one turn of the spiral is about 200 times the spiral bar diameter. In this case, for the strain energy capacity of the spiral at first spiral fracture, 70 to $100 \mathrm{MJ} / \mathrm{m}^{3}$ calculated from Eq.11 will give a better estimation than 110 to $150 \mathrm{MJ} / \mathrm{m}^{3}$ calculated from Eq. 10 .

Moreover, the strain distribution of the spirals or hoops along the column axis also needs to be taken into account for the estimation of the $U$. This is because the corresponding strainh energy stored in the core concrete has to be calculated from a theoretical or a measured stress-strain relation of confined concrete over a defined gauge length. That is, the longitudinal concrete strain is an average strain within the gauge length used for the concrete strain definition or measurement. Hence, the calculated strain energy of the concrete core does not usually just correspond to the strain energy stored in the damaged region concentrated within one hoop spacing at which the first hoop fracture occurs. The longitudinal concrete strain used in the stress-strain relation might mean an average strain within a plastic hinge region of the column over a length of one-third to a full section depth of the column. Therefore, if the buckled shape of the longitudinal bar is represented as in Fig.9, the average strain of the hoops within the above mentioned length of the column needs to be used for the estimation of the strain energy stored in the hoops. As a result, the value of $\mathrm{U}$ needs to be modified again based on the buckled shape expected.

If buckling over more than two hoop spacing is not expected prior to the hoop fracture, the value of $U_{\text { }}$ obtained from Eq.11 can be used without shrther modificaiton because the hoop strains distributed along the coulmn axis will be almost constant. However, if buckling is limited within one hoop spacing, the external work done on the longitudinal bars may hardly be transferred to the hoop reinforcement because such buckling condition corresponds to the case without a tie bar representing hoops in Fig. 5 and thus the last term in Eq. 6 must be eliminated. In this case, the proposed equations (Eqs.1,3 and 4) lose their validity because those equations are based on the assumption that the external work. done on the longitudinal bars is all transferred to the hoop reinforcement.

As a corrollary, it can be considered that the stored energy in the hoop reinforcement at first hoop fracture could be overestimated by 20 to $40 \%$ or more if Eq. 10 is used. In Eqs.1, 3 and 4, this overestimation may successfully compensate for the neglect of the absorbed energy in the longitudinal bars due to axial yielding in some cases but not always. Therefore, it can be considered that the equations proposed in the energy balance theory need to be modified or to be limited in their use.

\begin{tabular}{llll} 
A PROPOSED & ENERGY PRINCIPLE MODEL FOR A \\
\hline REINFORCED CONCRETE COLUMN SUBJECTED TO TO
\end{tabular} AXIAL COMPRESSION

Observed Failure Mechanism for concrete in Compression

In a conservative system of energy, such as the elastic behaviour of a member, the work performed by both internal and external forces is independent of the path travelled by these forces and hence the work can be determined only from the initial and the final positions of these forces. However, in the case of inelastic behaviour of a reinforced concrete member, the system is usually non-conservative because there exists internal frictions due to inelastic deformation of each constituent which includes cracking. Therefore the failure mechanism of the member, determined by the path of internal forces, becomes the key to estimate the internal work performed. In this study, the following failure mechanism is assumed for a reinforced concrete column under axial compression.

When a reinforced concrete column is compressed far into the inelastic range by an axial load, it can be assumed that shear siding surfaces are formed inside the core concrete with the propagation of micro cracks [11], as jllustrated in Fig.10. The shear sliding surfaces are either of a type $A$ or a type $B$. Shear sliding surfaces of type A separate the concrete core into top and bottom cones (in case of a circular column) or pyramids (in case of a square column) and side shells. Shear sliding surfaces of type $B$ separate the concrete core into two wedge shaped parts. This assumption is based on the failure modes usually observed in compression tests on circular or square columns. Figures 11 and 12 [10] show typical examples of the failure modes observed in such column tests [12]. In Fig.12, the two protruding bars which were provided to mount potentiometers passed through the concrete core and were originally straight bars. During testing the top and bottom bars begar to bend upward and downward, respectively, as the axial compressive displacement of the square concrete column increased. This phenomenon would be the result of the wedging action of the top and bottom concrete pyramids as illustated in Fig.10, type A.

\section{Proposed Failure Mechanism Model}

Based on this Eailure nechanism, the assumed role and behaviour of each concrete and steel constituent can be described and the proposed failure mechanisim model for a reinforced concrete column subjected to axial loading shown in Fig.13 can be developed.

The assumed role and behaviour of each constituent, with reference to Fig.13, is as follows: 
<smiles>CC=CP</smiles>
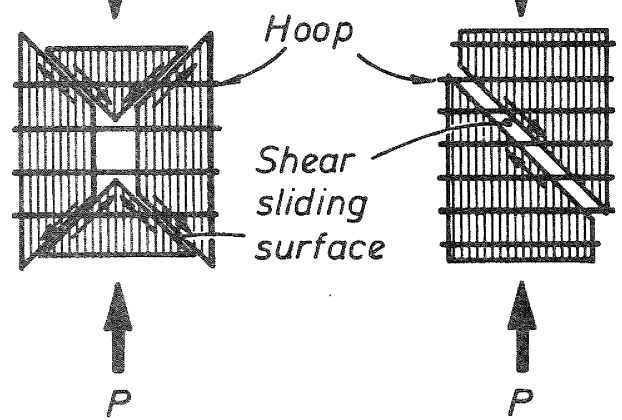

Type A

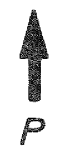

Type B

Fig. 10 Formation of Shear Sliding Surfaces in core concrete

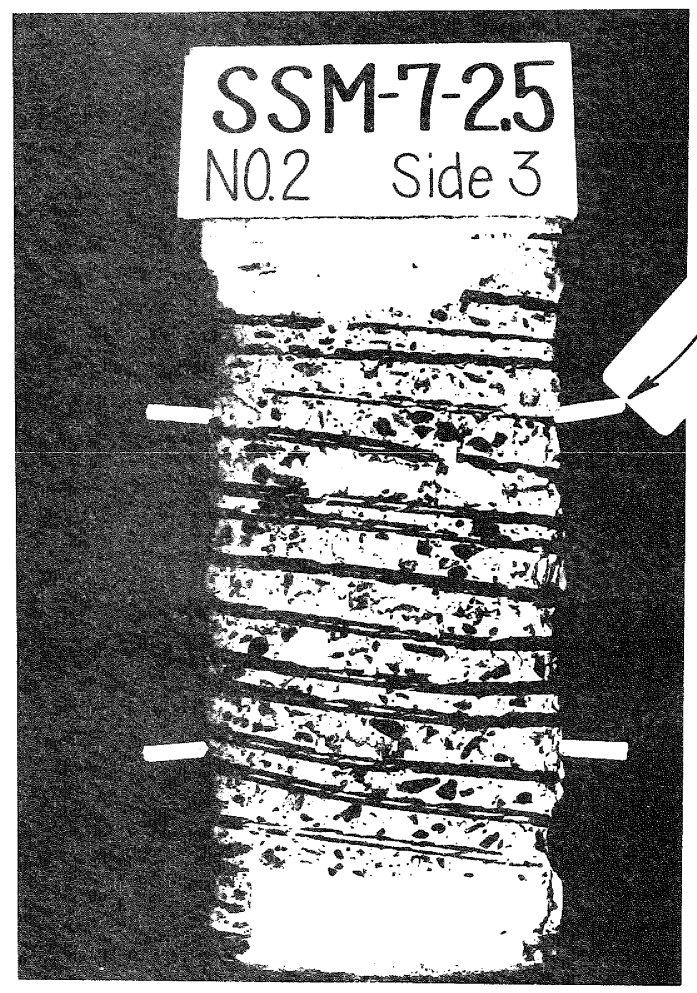

A buried bar to mount a potentiometer. It was straight and horizontal before loading. was straight and horizontal before loading.

Fig. 11 Typical Failure Mode of a Circular column
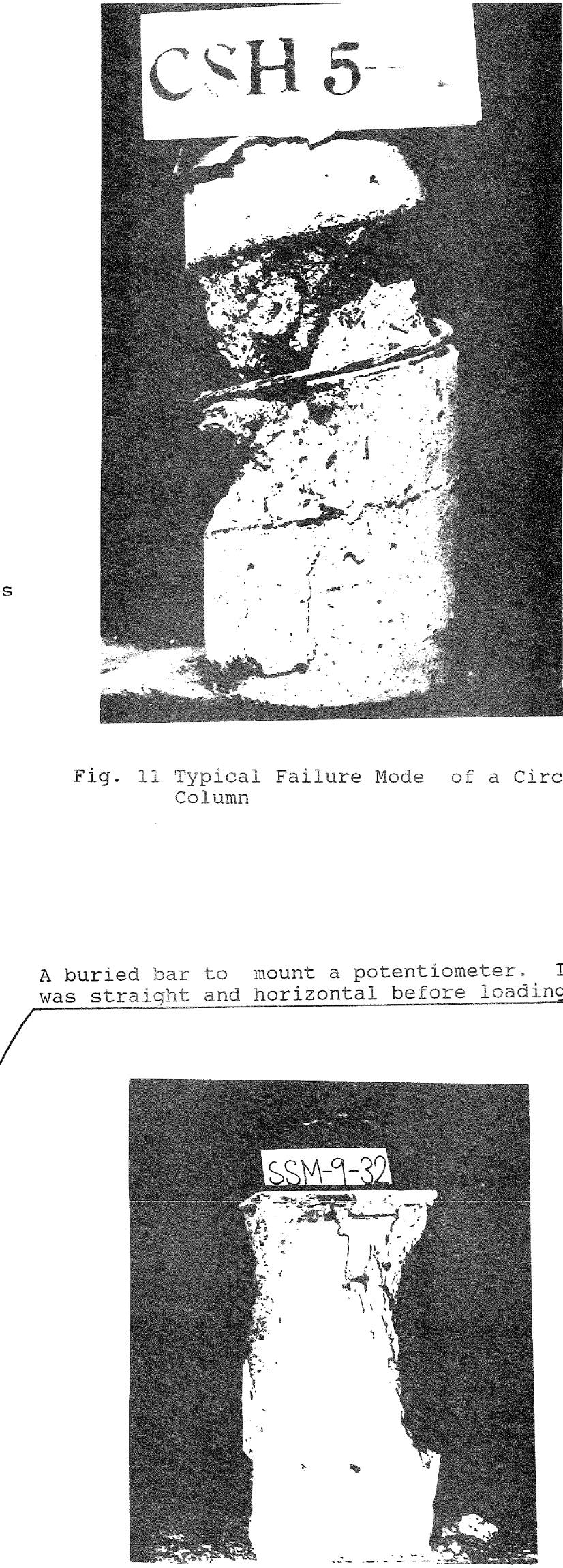

Fig. 12 Typical Failure Mode of Square Columns 
(1) Cover concrete: Works as à compression strut (spring $\mathrm{k}_{\mathrm{COV}}$ ) against the axial load until spaling is completed and thereafter vanishes.

(2) Core concrete: In the initial stage, works as a compression strut (spring $\mathrm{k}$ ) in the same manner as the cover concrete, until the complete formation of the shear sliding surfaces, and some percentage of the external work is transferred to hoops by poisson's effect as represented by a pantograph in Fig.13(a). The angle $*$ in the pantograph corresponds to the Poisson's ratio of the concrete treated as a unit solid material. It is assumed that the second stage commences with the complete formation of the shear sliding surfaces which is simultaneous with the complete spalling of cover concrete. After formation, the shear sliding surfaces act as a transformer which changes the axial load into lateral load by the wedging effect of the top and bottom cones in the case of type $A$, or wedge shaped lumps in the case of type B, shear sliding surfaces of Fig.10. Hence, the angle $\theta^{\prime}$ of the pantograph in Fig.13(b) can be determined from the inclination of the shear sliding surfaces. The friction between the shear sliding surfaces (spring $k_{\text {f }}$ ) also provides resistance against thẹ axial load.

(3) Longitudinal reinforcement: In the initial stage, works as a compression strut (spring $\mathrm{k}_{\mathrm{sC}}$ ) against the axial load. In the inal stage, after the onset of buckling, works as a pantograph which can transfer the axial load work to the hoop reinforcement by changing the load direction from axial direction to lateral direction. The angle $\theta$ " in Fig.13(c) can be determined from the buckling mode of the longitudinal bars.

(4) Hoop reinforcement: In the initial stage, works as lateral confinement which provides quasi-fluid pressure to the core concrete. In the second stage, after the formation of the shear sliding surfaces in the core concrete, works as hoops to prevent sliding of the top and bottom cones or the wedge shaped lumps until buckling of the longitudinal bars commences. In the final stage, works as anti-buckling support until the hoop fracture.

In the proposed failure mechanism model of Fig.13, in the initial stage where the core concrete can be treated as a unit solid body the improvement of the load carrying capacity of the confined concrete is attributed to the lateral pressure from the hoop reinforcement as a result of lateral expansion of the core concrete due to Poisson's effect. On the other hand, in the high strain region in the second stage after the formation of the shear sliding surfaces, the improvement of the load carrying capacity is attributed to the restraint against the shear sliding along the surfaces between the core concrete parts separated by cracks shown in Fig. 10 .
It is of interest that the angles $\theta, \theta^{\prime}$ and $\theta$ " in Fig.13 need not be determined in order to calculate the longitudinal concrete strain at first hoop fracture. This is because only the strain energy capacity of the hoop reinforcement up to its fracture is required to be determined for this case. Only when the stress-strain relation of the confined concrete needs to be computed step by step, it is necessary to determine the angles $\theta, \theta \rightarrow$ and $\theta "$.

In Fig.13, the initial gap ${ }^{1}$ esp between the spring $k$ and the logding plate corresponds toCf the axial displacement necessary to complete the spalling of cover concrete and to form the shear sliding surfaces. At the initial stage of loading, the rigid bar connector beside the spring $\mathrm{k}$ has a gap of $l^{\epsilon}$ and the pantograph below the spring $\mathrm{k} g$ can not be deformed due to the restrain ${ }^{\mathrm{S}}$ by the inserted rigid bar. This model for the longitudinal bars represents the situation expressed in Eqs.5 and 6 but neglecting the bending resistance of the longitudinal bars.

Energy Equation for the Proposed Failure Mechanism Model

Based on this failure mechanism model, the external work done on the column per unit length $U$ can be equated to the following internal $g_{\text {work. }}$

$$
U_{g}=U_{c o v}+U_{c o}+U_{c c f}+U_{s c r}+\alpha U_{s h}^{s}
$$

where $\mathrm{U}_{\mathrm{Cov}}=$ strain energy absorbed in cover concrete prior to complete spalling

$\mathrm{U}_{\mathrm{CO}}=$ strain energy absorbed in core concrete prior to complete formation of shear sliding surfaces

$\mathrm{U}_{\mathrm{Ccf}}=$ energy dissipated by friction between the shear sliding surfaces in the concrete core prior to first hoop fracture

$\mathrm{U}_{\mathrm{scr}}=$ strain energy absorbed in compression reinforcement due to axial yielding

U'sh = strain energy stored in hoop reinforcement at first hoop fracture in the case where the longitudinal bars are not buckled or are buckled within one hoop spacing

reduction factor for $U^{\prime}$ determined from the hoop strain distribution along the column axis.

Equation 12 can be equated to the external work expressed by Eq. 8 and hence,

$$
\begin{aligned}
U_{c c}+U_{s c} & +U_{c o v}=U_{c o v}+U_{c o}+U_{c c f} \\
& +U_{s c r}+\alpha U_{s h}^{\prime}
\end{aligned}
$$

Rearranging this equation,

$$
U_{c c}-U_{c o}=U_{c c f}+\alpha U^{\prime}{ }_{s h}-\left(U_{s c}-U_{s c r}\right)
$$

U scr may be expressed in the form of

$$
\mathrm{U}_{\mathrm{SCr}}=\beta \mathrm{U}_{\mathrm{SC}}
$$


where $\beta \quad$ ratio of strain energy absorbed in the longitudinal bars by axial yielding to the external work done on the longitudinal bars.

Substituting it into Eq.14,

$$
U_{c c}-U_{c o}=U_{c c f}+\alpha U_{s h}^{\prime}-(1-\beta) U_{S C}
$$

Equation 15 can be rewritten for a unit length of the column in the form of stresses and strains as

$$
\begin{aligned}
& A_{c c} \int_{0}^{c u} f_{c c} d \epsilon{ }_{c}-A_{c c} \int_{0}^{t} s p f_{c o} d \epsilon \\
& =A_{c c} \int_{\epsilon_{s p}}^{c u} f_{c c f} d \epsilon c+\alpha \rho{ }_{s}^{A} c c \int_{0}^{t s u} f_{s h} d \epsilon s h \\
& \text { - }(1-\beta) \rho c c^{A} c c \int_{0}^{t}{ }^{c u} \mathrm{f}_{s 1} \mathrm{~d} \epsilon \text { c }
\end{aligned}
$$

or for unit volume of the columns,

$$
\begin{aligned}
& \int_{0}^{\epsilon}{ }^{c u} f_{c c} d \epsilon-\int_{0}^{\epsilon} f_{c o} d \epsilon=\int_{\epsilon}^{c} c u f_{c c f} d \epsilon c \\
& +\alpha \rho s \int_{0}^{\epsilon}{ }^{s u} f_{s h} d \epsilon s h-(1-\beta) \rho c c \int_{0}^{t}{ }^{c u} f_{s l} d \epsilon c
\end{aligned}
$$

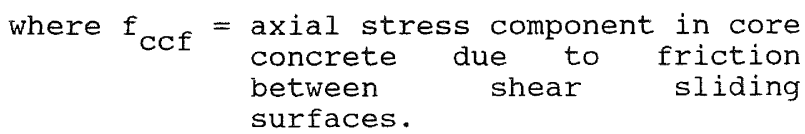
Using theoretical relations for $\mathrm{f}_{\mathrm{CO}_{f}^{\prime}} \mathrm{f}_{\mathrm{C}} \mathrm{E}$ ' fonfitudinal strain of the concrete core, and with adequate values of $t, \alpha, \beta$ and U' Eq.17 can be solved Scor $\epsilon^{\prime} \mathrm{c}^{\prime}$ by numerical trial and error methods.

\section{Values of the Terms in the Proposed Energy Equation}

Many theoretical curves for $f_{\mathrm{Cc}} \mathrm{f}_{\mathrm{co}}$ and $f$ have aleady been established, for example see Refs.1 and 14. Concerning $f$, the following relation can be assumed:

$$
\mathrm{f}_{\mathrm{cef}}=\gamma \mathrm{f}^{\prime} \mathrm{co}
$$

where

$$
\begin{aligned}
\gamma= & \text { constant determined by } \\
& \text { magnitude of friction between } \\
& \text { the shear sliding surfaces in } \\
& \text { the concrete core. } \\
f^{\prime}{ }_{c o}= & \text { compressive strength of plain } \\
& \text { concrete assumed to be } 85 \% \text { of } \\
& \text { the control cylinder strength. }
\end{aligned}
$$

Equation 18 is derived from the observation of compression tests on plain concrete cylinders or prisms. In the tests, the stress reduction in the strain softening region becomes gradual after reaching a longitudinal strain of 0.004 to 0.006 and thereafter a stress level of 0.1 to $0.2 \mathrm{f}^{\prime}$ is maintained $[11,14]$. This stress level can be considered to indicate the potential magnitude of the friction between the shear sliding surfaces formed in the confined concrete core.

As a value of $\epsilon$, 0.004 to 0.008 may be adequate. The actual value will depend on the strain gradient of the column section and on the quantity of transverse reinforcement. If there exists a large strain gradient (that is, a small neutral axis depth) the complete spalling of cover concrete is usually delayed due to a restraint by neighbouring concrete layers which stay at a smaller strain [13,14]. It has also been observed that a high quantity of transverse reinforcement results in plane of weakness between core and cover concretes which results in a lower [14]. For reinforced concrete columns subjected to concentric axial compression, a value for $t$ of 0.004 may be assumed because of absence of the strain gradient in the column section. For the reinforced concrete columns subjected to combined axial load and bending moment, a value for $\epsilon$ of 0.006 or more may be adequate if the transverse reinforcement provided in the columns is not extremely congested, as has been found appropriate in a previous study [15].

The value of $\alpha$ varies with the expected buckling mode of the longitudinal bars. The buckling mode can be expressed as a combination of the modes of a gross buckling and a local buckling as shown in Fig.14. If the expected local buckling is limited to within one hoop spacing without occurrence of the gross buckling $\alpha=1$ may be adopted because the hoop strain distribution along the column length will be approximately constant. In the case of a column with the gross buckling of longitudinal reinforcement as shown in Fig.9, a can be calculated as follows. If the core diameter of column is $d_{c^{\prime}}$ the total height of column is $3 d$, and the gauge length of the concrete core strain measurement is $d$, the gross buckled shape of the longltudinal bars may be approximated by a sinusoidal curve expressed by the following equation.

$$
y=\frac{a}{2}\left(1-\cos \frac{2 \pi \underline{x}}{3 d}{ }_{c}\right)
$$

$$
\begin{aligned}
\text { where a }= & \text { the maximum of lateral } \\
& \text { displacement the } \\
& \text { longitudinal bar at the mid- } \\
& \text { height of the column } \\
3 \mathrm{~d}_{\mathrm{C}}= & \text { the height of the column (see } \\
& \text { Fig.14(a)) }
\end{aligned}
$$

In Eq.19 it is assumed that the lateral expansion of the column at each end is negligible because even spalling of cover concrete cannot usually be observed in the end portions of the column, due to the effects of friction between the loading plate and the contact surface of the concrete at each end of the column. The average lateral displacement within the gauge length 1 of $d$ in the middle third of the column dan be expressed in the form 


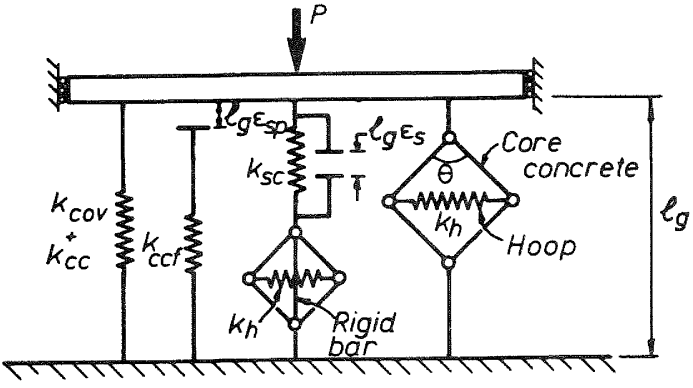

(a) Initial Stage

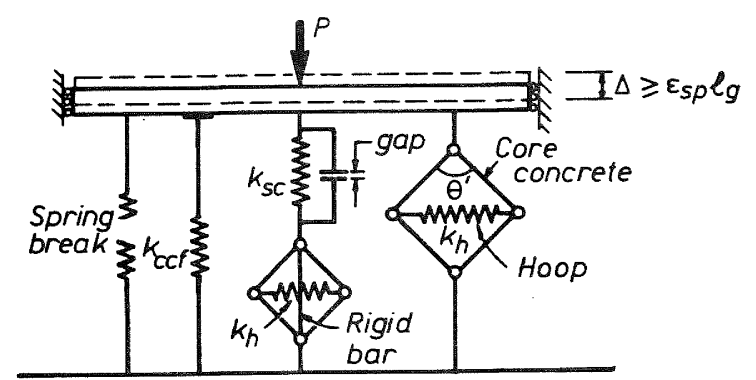

(b) Second Stage (After formation of shear sliding surfaces but without buckling of longitudinal bar )

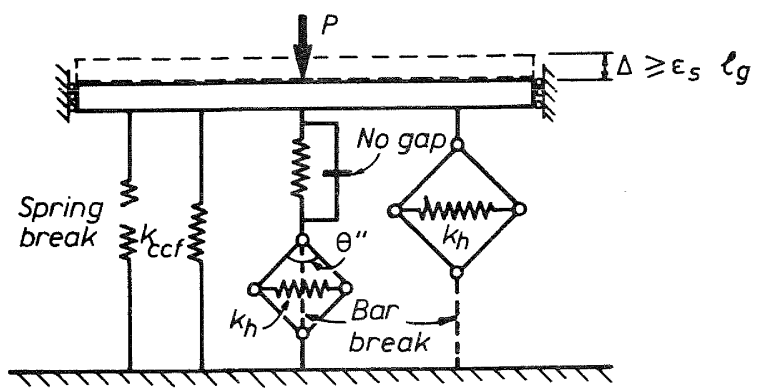

(c) Final Stage (After onset of longitudinal bar buckling)

Fig. 13 Proposed Failure Mechanism Model for a Reinforced Concrete column Subjected to Axial Loading

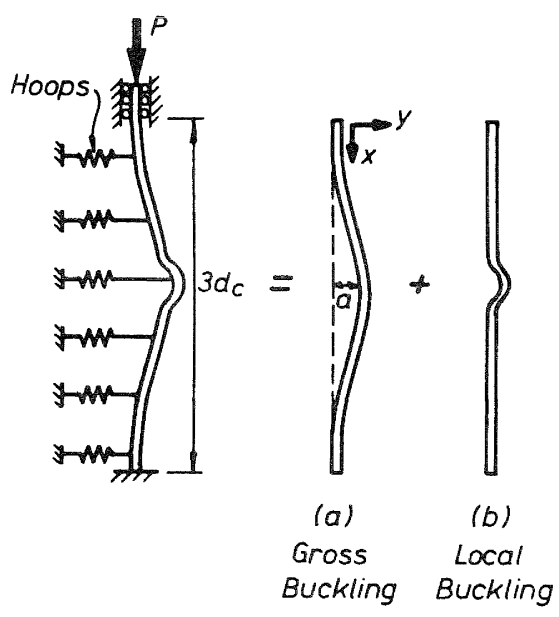

Fig. 14 Buckling Modes of a Compressed Longitudinal Bar in a Reinforced Concrete Column

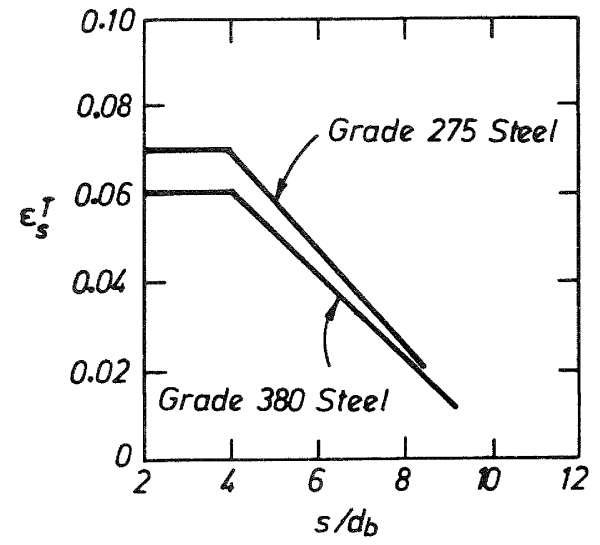

Fig. 15 Buckling Strain of a Longitudinal Bar and the Corresponding Hoop spacing [16]

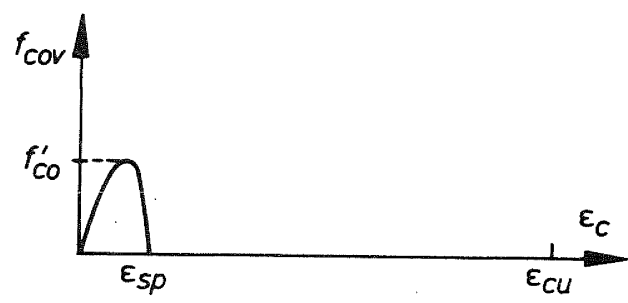

(a) Cover and Core Concrete Before Formation of Shear Sliding Surface (Spring $k_{\text {cov }}+k_{c c}$ )

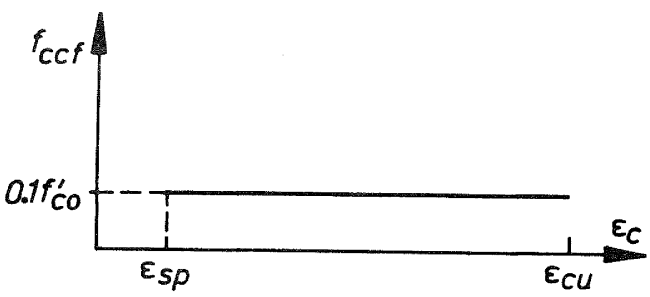

(b) Core Concrete After Complete Formation of Shear Sliding Surface (Spring $k_{\text {CCf }}$ )

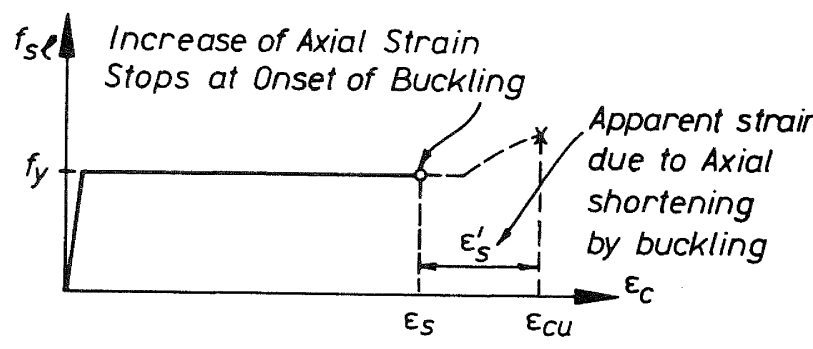

(c) Longitudinal Bars (Spring $k_{s c}$ )

Fig. 16 Stress-Strain Behaviour of Concrete and steel Constituents 


$$
y_{\text {ave }}=\frac{1}{d_{c}} \int_{d_{c}}^{2 d} \frac{{ }^{c}}{2}\left(1-\cos \frac{2}{3} \pi_{c} \underline{x}\right) d x=0.91 a
$$

Hence, in this case $a=0.9$ might be an adequate value. If the local buckling occurs over several hoop spacings in addition to the above gross buckling, the value of $a$ needs to be reduced to a value which is less than 0.9. If the local buckling in addition to the above gross buckling does not occur or is limited within one hoop spacing, the value of $\alpha$ need not be reduced from 0.9.

The value of $\beta$ which express the ratio of strain energy absorbed in the compression reinforcement by axial yielding to external work done on the compression reinforcement is not so simple to calculate theoretically, because it depends on several factors such as the hoop spacing, the stiffness of the hoop reinforcment against the longitudinal bar buckling, the bending stiffness of the longitudinal bar in plastic buckling, and so on. However, the value of $\beta$ could be approximated using Fig.15 from Ref.16, which shows the theoretical buckling strain of a longitudinal bar $\epsilon T$, in relation to the hoop spacing assuming that the buckling occurs only within one hoop spacing. It is evident that Fig.15 gives an upper bound for the compression strain at buckling because of the buckling mode assumed.

Using this $\epsilon_{S}$ T value, $\beta$ may be approximated in the form

$$
\beta=\frac{\epsilon_{S}^{T}}{\epsilon_{c u}}
$$

If Eq. 21 is used with value of ${ }^{T}$ from Fig.15, a check might be necessary to determine whether the error in $\beta$ due to overestimation of $t$ is negligible or not taking into account the expected buckling mode of the longitudinal reinforcement. However, the error in the value of $\beta$ usually does not affect the accuracy of the prediction of t greatly because the total energy stored in the longitudinal bars is less than a half of the strain energy stored in a well confined concrete core even for high compression reinforcement ratios of about $3 \%$ (see $U_{\mathrm{CC}}$ and $\mathrm{U}_{\mathrm{SC}}$ in Table 2).

Several tensile tests on reinforcina steel bars have been conducted with strain measurement using various gauge lengths [10] in order to estimate the values of Eqs. 10 and 11 which are used to calculate U in the energy balance theory and U' inh the proposed theory, respectively. The test results are listed with the results of other researchers $[1,16]$ in Table 1 . As mentioned in the previous section, the measured strains vary significantly with the change of the gauge length adopted in the particular test and thus the corresponding strain energies calculated from those measured strains also vary. It is suggested that for the value of Eq.11
Which is used to calculate $U^{\prime}$ the average of values obtained by the shuthor's test [10] and by Mander et al [1] which are given in Table 1 could be used, namely in this case:

The strain energy stored at ultimate strength of steel perr unit volume of reinforcement $=84 \mathrm{MJ} / \mathrm{m}^{3}$.

\section{Comparison of the Predictions of the} Proposed Theory with the Results of Tests

In order to assess the accuracy of the theory proposed here, the predictions of the theory were compared with the test results obtained from the monotonic axial compression tests on circular columns with core diameter of $450 \mathrm{~mm}$ and octagonal columns with core diameter of $384 \mathrm{~mm}$ conducted by Mander et al [1] and Zahn et al [16], respectively. In those tests, the concrete strengths measured on control cylinders varied from 28 to $33 \mathrm{MPa}$. For the spirals, as hoop reinforcement, 10 to $12 \mathrm{~mm}$ diameter plain bars from both 275 and 380 Grade steel were used. For the longitudinal reinforcement, 16 to $24 \mathrm{~mm}$ diameter deformed bars from Grade 275 steel were used except for one column (C.12 in Table 2) in which Grade 380 longitudinal bars were used.

The stress-strain relations for the cover and core concrete and the longitudinal reinforecement assumed in the proposed failure mechanism model are shown in Fig.16. For the estimation of $U_{\mathrm{Co}}$ the following empirical equation was used.

$$
U_{c o}=A_{c c} 0.017 \sqrt{\mathrm{f}^{\prime}{ }_{c o}} \mathrm{KJ} / \mathrm{m}
$$

where $A_{C C}$ in $\mathrm{m}^{2}$ and $f^{\prime}{ }_{\mathrm{CO}}$ in MPa.

Eq. 22 was obtained in the statistical study by Mander et al $[1,2,3]$. For the value of ' because no serious strain gradient was present in the section due to the concentric loading, $=0.004$ was assumed. A value of $\alpha \underline{\underline{p}} 0.9$ was used because all of the tests columns had similar ratios of the column diameter, height and gauge length as that assumed in the derivation of Eq.20. A value of $\beta=0.9$ was estimated, because the ratios of hoop spacing to the longitudinal bar diameter $\left(s / d_{b}\right)$ were less fhan 4 in most test columns and hence $\mathrm{c}$ obtained from Fig. 15 is close to or greater than t measured in those tests. For $U$ and $U$ Cu the values directly obtained from sfie measured load-axial strain relations were used. $U$ was calculated assuming the $\gamma=0.1$ Inf Eq.18. U' $\mathrm{U}^{\prime}$ was calçulated

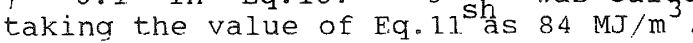

The properties of eighteen concrete columns tested at the University of canterbury $[1,16]$ and the calculated results are listed in Table 2 .

In order to check the agreement of the theoretical value with the experimental value, the ratios of

$$
I_{a g}{ }^{T}=\frac{\left\{\alpha U_{s h}+U_{c c f}-(1-\beta) U_{s c}\right\}}{\left(U_{c c}-U_{c o}\right)}
$$


Table 1. Measured Strain Energy Capacity of Reinforcing Bars

\begin{tabular}{|c|c|c|c|c|c|c|c|c|c|c|}
\hline \multirow[t]{2}{*}{ Study } & \multirow[t]{2}{*}{$\begin{array}{c}\text { Reinforcing } \\
\text { Bar }\end{array}$} & \multirow{2}{*}{\begin{tabular}{|c|} 
Yield \\
Strength \\
in \\
$\mathrm{MPa}$
\end{tabular}} & \multirow{2}{*}{\begin{tabular}{|c|} 
Ultimate \\
Strength \\
in \\
$\mathrm{MPa}$
\end{tabular}} & \multirow{2}{*}{\begin{tabular}{|l|} 
Strain at \\
Ultimate \\
Strength \\
GL $=5 d_{b}$
\end{tabular}} & \multirow{2}{*}{$\begin{array}{c}\text { Fracture } \\
\text { Strength } \\
\text { in } \\
\mathrm{MPa}\end{array}$} & \multicolumn{2}{|c|}{ Fracture Strain } & \multicolumn{2}{|c|}{\begin{tabular}{|c|} 
Strain Energy \\
Calculated \\
by Eq. 10 in $\mathrm{MJ} / \mathrm{m}^{3}$
\end{tabular}} & \multirow{2}{*}{$\begin{array}{c}\text { Strain Energy } \\
\text { Calculated } \\
\text { by } \mathrm{Eq.11} \text { in } \mathrm{MJ} / \mathrm{m}^{3} \\
\mathrm{GL}=5 \mathrm{~d} \mathrm{~b}\end{array}$} \\
\hline & & & & & & $\mathrm{GL}=5 \mathrm{~d}_{\mathrm{b}}$ & $\mathrm{GL}=20 \mathrm{~d}_{\mathrm{b}}$ & $\mathrm{GL}=5 \mathrm{~d}_{\mathrm{b}}$ & $\mathrm{GL}=20 \mathrm{~d}_{\mathrm{b}}$ & \\
\hline \multirow{5}{*}{$\begin{array}{l}\text { Tanaka } \\
{[10](\star 1)}\end{array}$} & HD24 & 432 & 588 & 0.169 & 415 & 0.289 & 0.199 & 151 & 107 & 91 \\
\hline & HD20 & 485 & 644 & 0.148 & 475 & 0.265 & 0.177 & 152 & 104 & 87 \\
\hline & $\phi 12$ & 305 & 446 & 0.246 & 298 & 0.415 & 0.288 & 163 & 117 & 100 \\
\hline & $\phi 10$ & 308 & 431 & 0.250 & 288 & 0.420 & 0.293 & 161 & 117 & 100 \\
\hline & Average & & & & & & & 157 & 111 & 95 \\
\hline \multirow{5}{*}{$\begin{array}{l}\text { Mander et al } \\
{[1](\star 2)}\end{array}$} & $\phi 16$ & 295 & 433 & 0.19 & - & - & 0.25 & - & 98 & 74 \\
\hline & HD16 & 360 & 567 & 0.15 & - & - & 0.24 & - & 121 & 77 \\
\hline & D20 & 286 & 429 & 0.18 & - & - & 0.28 & - & 111 & 69 \\
\hline & D24 & 260 & 567 & 0.18 & - & - & 0.29 & - & 111 & 70 \\
\hline & Average & & & & & & & & 110 & 73 \\
\hline \multirow{3}{*}{$\begin{array}{l}\text { Zahn et al } \\
{[16] \quad(* 3)}\end{array}$} & $\phi 12$ & 328 & 492 & - & - & - & 0.24 & - & 110 & - \\
\hline & $\mathrm{H} \phi 10$ & 466 & 688 & - & - & - & 0.175 & - & 110 & - \\
\hline & Average & & & & & & & & 110 & \\
\hline
\end{tabular}

(*1) The values for each bar are average values from 5 test pieces

$(\star 2)$ Gauge length $=203 \mathrm{~mm}\left(=8-13 \mathrm{~d}_{\mathrm{b}}\right)$

(*3) Gauge length $=203 \mathrm{~mm}\left(=17 \sim 20 \mathrm{~b}_{\mathrm{b}}\right)$

for the theory proposed in this paper and

$$
I_{a g}{ }^{M}=\frac{\left(U_{s h}-U_{s c}\right)}{\left(U_{c c}-U_{c o}\right)}
$$

for the energy balance theory are listed in Table 2. In Eq.24, U was calculated using Eq.10. The average percentage error given by $I^{T}$ is $12 \%$ with a maximum percentage error uf $33 \%$, while those percentage errors for $\mathrm{I}^{\mathrm{M}}$ are $17 \%$ and $77 \%$ respectively. As predicted, in case of energy balance theory which neglects the strain energy absorbed by the axial yielding of longitudinal bars, the largest error is found for test column U.2 which has a small amount of hoop reinforcement and a large amount of longitudinal reinforcement.

The calculated results for the ultimate concrete strain, defined as that longitudinal compressive stain of concrete where the hoops first fracture, using the modified theory are also listed in Table 2 . In the calculation, a bilinear stressstrain relation determined by the measured yeild strength of steel was used for the longitudinal reinforcement. For the confined core concrete, the stress-strain model due to Mander et al $[1,2,3]$ was used, The calculated ultimate concrete strains compare quite well with the measured values in most cases. However, it should be noted that any stress-strain model for confined concrete does not perfectly predict the experimentai stress-strain behaviour and hence these calculated ultimate concrete strains include the error due to any inaccuracy in the stress-strain model used. It is evident from the comparison in Table 2 that the ultimate concrete compressive strain at first hoop fracture can be well predicted using the theory proposed in this study.

\section{CONCLUSIONS}

To estimate the ultimate concrete compressive strain, defined as that strain where first hoop fracture occurs, a theoretical method using an energy principle model was established in this study. The basic idea of this method originated from the theory referred to as the energy balance theory by Mander et al. The following modifications to the energy balance theory were carried out to obtain the method proposed here:

(1) In the energy balance theory, the relationship between external work done on a reinforced concrete column and the corresponding internal work performed is not completely stated. In the proposed method, the above relationship is clarified by introducing a failure model for a rienforced concrete column subject to axial compression load.

(2) The strain energy absorbed in the longitudina.i reinforcement due to axial compressive yielding is taken into account in the proposed method. It is neglected in the energy balance theory.

(3) The energy dissipated by friction between shear sliding surfaces formed in the concrete core is considered on the basis of a proposed failure model in the proposed method. This energy 


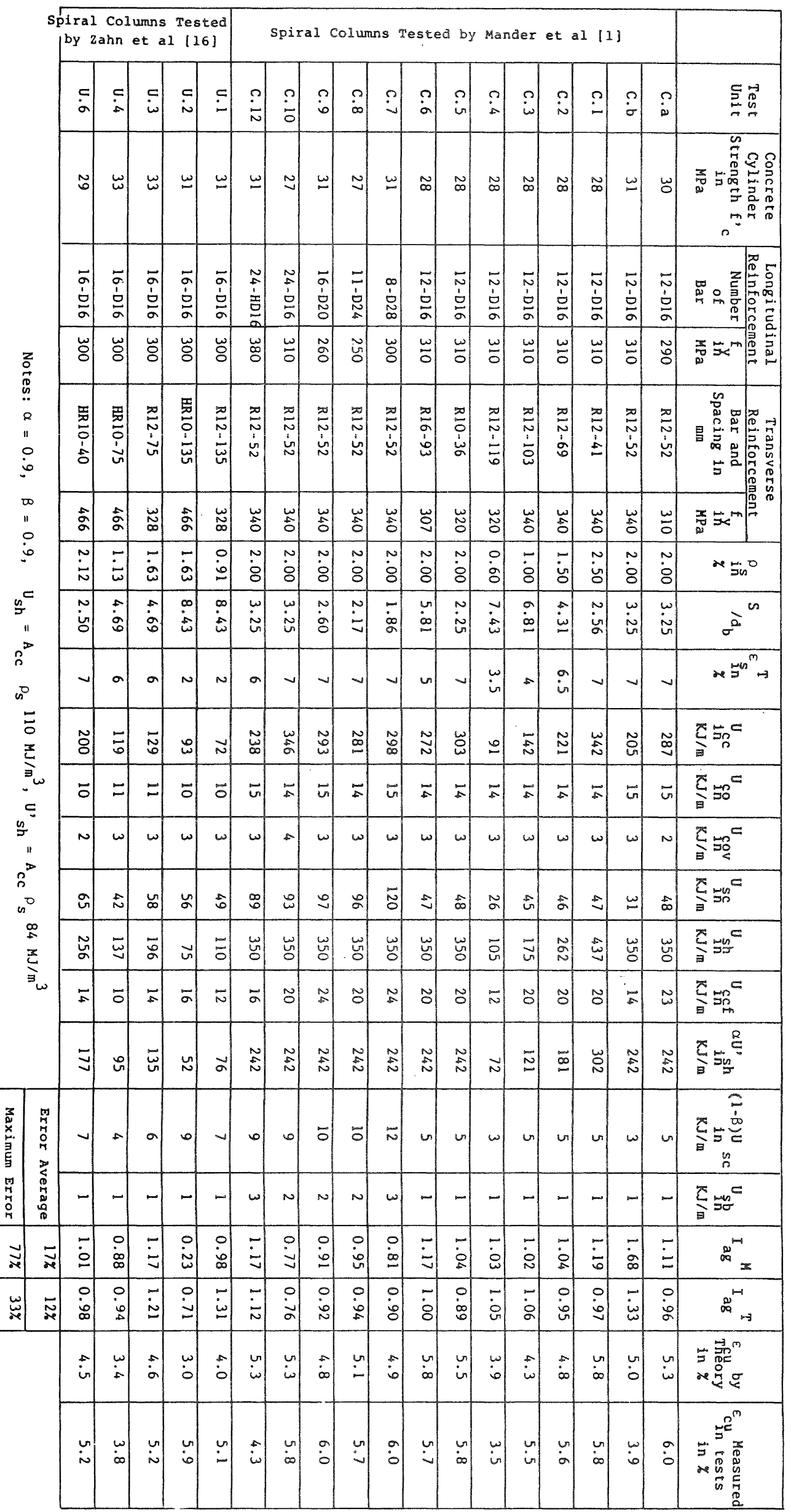

品

要竜

贻

$\vec{x}$

总 
factor is not included in the energy balance theory.

(4) One of the key aspects in the prediction of the occurrence of the hoop fracture is a proper estimate of the strain energy stored in the hoop reinforcement at the stage of hoop fracture. In the energy balance theory it was assumed that all parts of the hoop reinforcement simultaneously reached fracture strain when the first hoop fracture occurred. In the proposed method the strain energy stored in the hoop reinforcement is estimated using an assumed strain distribution in the hoop reinforcement where only the necking part of the hoop bar reaches the fracture strain and the strains in the remaining parts of the hoop bar are equal to or less than the strain at the ultimate strength of the steel.

The proposed method was applied to the results of concentric load tests on 18 reinforced concrete columns conducted at the University of Canterbury. The theoretical values calculated by the proposed method agreed well with the test results. It is considered that the proposed method can be used to estimate with reasonable accuracy the ultimate longitudinal compressive concrete strain defined as the strain at first hoop fracture.

In the proposed method on $\perp y$ reinforced concrete columns subjected to axial compression are considered. Further study to include different failure modes such as due to combined axial load, flexure and shear is recommended.

\section{REFERENCES}

1. Mander, J.B., Priestley, M.J.N. and Park, R., "Seismic Design of Bridge Piers", Research Report 84-2, Department of Civil Engineering, University of Canterbury, Feb. 1984, p. 483 .

2. Priestley, M.J.N. and Park, R., "Strength" and Ductility of Bridge Substructures", Road Research Unit Bulletin 71, National Roads Board, Wellington, New Zealand, 1984, p.120.

3. Mander, J.B., Priestley, M.J.N. and Park, R., "Theoretical stress-strain Model for Confined Concrete", structural Engineering, American Society of civil Engineers (to be published).

4. Iyenger, K.T.R.J., Desayi, P. and Reddy, K.N., "Stress-Strain Characteristics of concrete confined in Steel Binders", Magazine of Concrete Research, Vol. 22, No. 72, Sept. 1970, pp.173-184.

5. "Code of Practice for the Design of Concrete Structures (NZS 3101, part 1:1982)" and "Commentary on the Design of concrete structures (NZS 3101, Part 2:1982)", Standard Association of New Zealand, Wellington.
5. Engesser, F., "Ueber die Knickfestigkeit..' gerader stäbe", Zeitschrift für Architektur und Ingenieurwesen, Vol. 35, 1889.

7. Engesser, F., "Knickfragen" Schweizerische Bauzeitung, Vol. 26 1895.

8. von Kármán, T., "Untersuchungen über Knickfestigkeit", Mitteilungen über Forschungsarbeiter auf dem Gebiete des Ingenieurwesens, Berlin, No. 81, 1910.

9. Shanley, F.R., "Inelastic column Theory", Journal of the Aeronautical. Sciences, Vol. 14, No. 5, 1947.

10. Tanaka, H., "Effect of Lateral Confining Reinforcement or the Ductile Behaviour of Reinforced Concrete Columns", PhD thesis in preparation, University of Canterbury.

11. Watanabe, F., "Complete Stress-Strain curve for concrete in concentric Compression", Mechanical Behaviour of Materials, Proceedings of the 1971 International Conference on Mechanical Behaviour of Materials, Vol. 4, pp.153-161.

12. Muguruma, H., Watanabe, F., Tanaka, H. Sakurai, K. and Nakamura, E. "Effect of Confinement by High Yield strength Hoop Reinforcement upon the compressive Ductility of Concrete", Proceedings of the Twenty-Second Japan Congress on

Material Research, The society of Materials Science, Japan, 1979. pp.377-382.

13. Sturman, G.M., Shah, S.P. and Winter, G. "Effect of Flexural strain Gradients on Microcracking and StressStrain Behaviour of Concrete", ACI Journal, 62, 1965, pp.805-822.

14. Park, R. and Paulay, T., "Reinforced Concrete Structures", John Wiley and Sons, New York, 1975, p.769.

15. Tanaka, H., Park, R. and McNamee, B., "Anchorage of Transverse Reinforcement in Rectangular Reinforced Concrete Columns in Seismic Design", Bulletin of the New Zealand National Society for Earthquake Engineering, Vol. 18, No. 2. June 1985, pp.165-190.

16. Zahn, F.A., Park, R: and Priestley M.J.N., "Design of Reinforced Concrete Bridge Columns for strength and Ductility" Research Report 86-7, Department of Civil Engineering, University of Canterbury, March 1986 , p. 380 